\title{
Commentary: Endograft repair of complicted aortic dissection in Marfan patients
}

\author{
R. Scott Mitchell, MD
}

\author{
From the Stanford University Medical Center, Falk Cardiovascular Research Center, Stanford, Calif. \\ Disclosures: Author has nothing to disclose with regard to commercial support. \\ Received for publication Aug 3, 2018; accepted for publication Aug 7, 2018. \\ Address for reprints: R. Scott Mitchell, MD, Stanford University Medical Center, Falk Cardiovascular Research \\ Center, 300 Pasteur Dr, Stanford, CA $94305-5407$ (E-mail: rsmitch@stanford.edu). \\ J Thorac Cardiovasc Surg 2019;157:e303 \\ 0022-5223/\$36.00 \\ Copyright (c) 2018 Published by Elsevier Inc. on behalf of The American Association for Thoracic Surgery \\ https://doi.org/10.1016/j.jtcvs.2018.08.023
}

Faure and colleagues ${ }^{1}$ are to be congratulated for their courageous study using endograft technology in patients with Marfan syndrome. Most of us avoid stent grafting in this population unless absolutely necessary. Given the difficulties of managing these patients with complicated acute type B aortic dissection in both the short and long term with open techniques, the addition of these techniques will greatly facilitate our management of these patients. However, some caveats remain. Although not experienced in this report, thoracic stent grafts in the distal arch do have the possibility of producing an acute retrograde type A aortic dissection, which further complicates management of this difficult disease. Also, early in our experience with acute type B aortic dissection, we experienced an episode of paraplegia after implanting a $20-\mathrm{cm}$ endograft and thereafter tried to minimize the extent of distal coverage. Additional coverage with uncovered stents does not appear to increase that incidence.

We also have some good follow-up to 21 years, although not in a patient with Marfan syndrome, suggesting that this management strategy is both effective and durable. It is hoped that new technology will be developed to allow distal aortic expansion with some fenestrated tubular device that

\section{Reference}

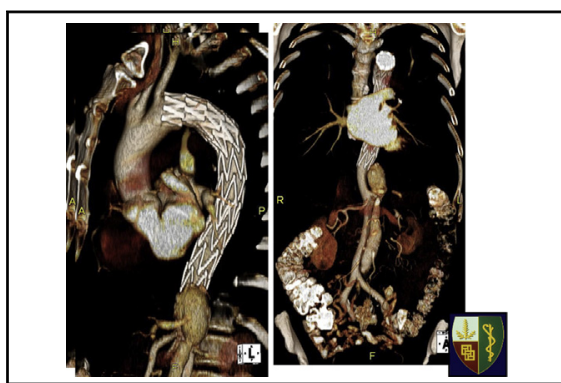

The 21 -year follow-up computed tomography angiography of endograft treatment of complicated acute type B aortic dissection.

\section{Central Message}

First-time experience with endograft repair of complicated acute type B aortic dissection in patients with Marfan syndrome.

See Article page 1787 in the November 2018 issue.

will be less likely to cause intimal tears than uncovered "Z" stents and allow perfusion of intercostal and lumbar arteries, as well as all abdominal visceral arteries. We look forward to longer-term follow-up of these patients in regard to the late integrity of these repairs.

1. Faure EM, El Batti S, Abou Rjeili M, Ben Abdallah I, Julia P, Alsac J-M. Stentassisted, balloon-induced intimal disruption and relamination of aortic dissection in patients with Marfan syndrome: midterm outcomes and aortic remodeling. $J$ Thorac Cardiovasc Surg. 2018;156:1787-93. 